\title{
Free-running L-band VCSEL for 1.25 Gbps hybrid radio-fiber cloud optical interconnects
}

Saldaña Cercos, Silvia; Prince, Kamau ; Roubeau, F.; Lim, S.; Neumeyr, C.; Ortsiefer, Markus; Rönneberg, E.; Aupetit-Berthelemot, C.; Tafur Monroy, Idelfonso

\author{
Published in: \\ OFC/NFOEC Technical Digest
}

Publication date:

2012

Document Version

Publisher's PDF, also known as Version of record

Link back to DTU Orbit

Citation (APA):

Saldaña Cercos, S., Prince, K., Roubeau, F., Lim, S., Neumeyr, C., Ortsiefer, M., Rönneberg, E., AupetitBerthelemot, C., \& Tafur Monroy, I. (2012). Free-running L-band VCSEL for 1.25 Gbps hybrid radio-fiber cloud optical interconnects. In OFC/NFOEC Technical Digest (pp. JTh2A.33). Optical Society of America.

\section{General rights}

Copyright and moral rights for the publications made accessible in the public portal are retained by the authors and/or other copyright owners and it is a condition of accessing publications that users recognise and abide by the legal requirements associated with these rights.

- Users may download and print one copy of any publication from the public portal for the purpose of private study or research.

- You may not further distribute the material or use it for any profit-making activity or commercial gain

- You may freely distribute the URL identifying the publication in the public portal 


\title{
Free-running L-band VCSEL for 1.25 Gbps hybrid radio-fiber cloud optical interconnects
}

\author{
S. Saldaña Cercós ${ }^{1 *}$, K. Prince ${ }^{1}$, F. Roubeau ${ }^{2}$, S. Lim ${ }^{1}$, C. Neumeyr ${ }^{3}$, M. Ortsiefer ${ }^{3}$ \\ E. Rönneberg ${ }^{3}$, C. Aupetit-Berthelemot ${ }^{2}$ and I. Tafur Monroy ${ }^{1}$ \\ ${ }^{1}$ DTU Fotonik, Technical University of Denmark, 2800 Kgs. Lyngby, Denmark \\ ${ }^{2}$ Ecole Nationale Supérieure d'Ingénieur de Limoges dpt. C2S2, Limoges Cedex, France \\ ${ }^{3}$ Vertilas GmbH, Garching, Germany \\ *s092705@student.dtu.dk
}

\begin{abstract}
We demonstrate a free-running directly-modulated $1580 \mathrm{~nm}$ VCSEL suitable for hybrid wireless/optical interconnects supporting cloud data centers. Error-free transmission at 1.25 Gbps was achieved after $6.5 \mathrm{GHz}$ wireless link and $1 \mathrm{~km}$ bend-insensitive fiber.
\end{abstract}

OCIS codes: (200.4650) Optical interconnects, (060.2360) Fiber optics links and subsystems.

\section{Introduction}

The demand for higher bandwidth, flexibility and reliability in data center applications has encouraged research into cloud computing architectures, focusing on efficient data centers implementing cost-effective, scalable, parallel optical interconnects [1]. Communication bottlenecks have been considered as one the biggest challenges in growing data centers; this motivates wavelength division multiplex (WDM) optical interconnects [2] for providing data bandwidth scalability [3] in highly-aggregated data traffic links [4-6]. Hybrid wireless-optical interconnect systems can provide alternate data paths between cloud nodes, allowing further traffic scaling or providing improved service reliability [7].

Vertical-cavity surface-emitting laser (VCSEL) devices are suitable for high-density cloud applications due to their compact size and low operating current levels. VCSEL operation without temperature or wavelength controls can further reduce energy consumption and transmitter complexity. In a wavelength division multiplex (WDM) scenario, compact L-band (1565 nm to $1625 \mathrm{~nm}$ ) VCSEL transmitters enhance bandwidth scaling [3] by increasing wavelength channelization. As physical space constraints in a cloud data center environment encourages high server density, optical fiber of type G.657 [8] bend-insensitive fiber (BIF) is recommended. BIF has optical characteristics similar to G.652 single-mode fiber (SMF), but its reduced macro-bending losses enable tighter installation clearances of the optical plant infrastructure and hence increased node density within the cloud server installation.

Previously, optical injection locking (OIL) enabled VCSEL transmitters operating at $850 \mathrm{~nm}$ [9] and $1540 \mathrm{~nm}$ [10] wavelength to achieve $3 \mathrm{Gbps}$ modulation in $60 \mathrm{GHz}$ radio over fiber (RoF) systems. Impulse radio ultra wide-band (IR-UWB) transmission over $2 \mathrm{~m}$ wireless link was reported at $1 \mathrm{Gbps}$ using a $850 \mathrm{~nm}$ VCSEL device [11]. We extend on previous work with L-band VCSELs [12] and hybrid radio/fiber links [11] by introducing a novel free-running L-band VCSEL operating at $1580 \mathrm{~nm}$ into a hybrid radio/fiber interconnect. Error-free transmission, with bit error rate (BER) below $10^{-9}$, was achieved at a data rate of $1.25 \mathrm{Gbps}$, after $55 \mathrm{~cm}$ air link and $1 \mathrm{~km}$ G.657 BIF. This represents the first known demonstration of free-running L-band VCSEL devices in implementing hybrid radio/fiber links for hybrid optical interconnect architectures.

\section{$2 \quad 1580$ nm VCSEL Characterization}

L-band VCSELs are suitable for broadband cloud optical interconnects due to their reduced operating current requirements and small size; wavelength tuning of such devices may also be exploited for WDM transmission. We implemented a novel $1580 \mathrm{~nm}$ VCSEL of type Vertilas VL-1585-10-SE-T4. This device has threshold current of $0.85 \mathrm{~mA}$, provides $3.9 \mathrm{~mW}$ optical power at $25^{\circ} \mathrm{C}$, and is operable without temperature or wavelength control. The prototype VCSEL used was not pigtailed; a cleaved SMF pigtail was aligned to collect the output beam at the device aperture. The DC characterization of this device, in terms of power and wavelength response to applied bias current, 
are presented in Fig. 1a The inset shows a sample optical spectrum obtained; un-modulated CW (solid, black) and modulated (red, dash) output. Device wavelength varied between $1575 \mathrm{~nm}$ and $1580 \mathrm{~nm}$; the maximum optical power obtained was $0.6 \mathrm{~mW}(-2.55 \mathrm{dBm})$; side-mode suppression ratio (SMSR) was $42 \mathrm{~dB}$.

\section{System Architecture}

WDM optical interconnect infrastructures implementing alternate wireless signaling paths can significantly improve performance in a cloud data server center architecture by relieving communication bottlenecks [2] and improving reliability [7]. The layout of a cloud-server architecture in which the WDM optical interconnects (solid, blue) provide a broadband communication platform is shown in Fig. 2a, alternate wireless connectivity (dash, red) may be implemented to enable continued cloud service operation in the event of link or node failure.

The evaluation layout used is presented in Fig. $2 \mathrm{~b}$, At the cluster node, the signal was generated by a pulse pattern generator providing non-return to zero on-off key (NRZ-OOK) pulses; pseudo-random binary sequence (PRBS) data pattern of length $2^{7}-1$ bits was used. Electrical radio-frequency (RF) mixer was used to up-convert the signal onto a 6.5 GHz RF carrier; the amplitude-shift key signal thus obtained and amplified prior to wireless transmission. Omnidirectional antennas were used on both ends of the $55 \mathrm{~cm}$ wireless link; these were of type Geozondas AU-3.1G10.6G1 , specified for $10 \mathrm{dBi}$ gain at $6 \mathrm{GHz}$. At the switch node, the received RF signal was amplified and down-converted to baseband by a matched RF mixer. In practice, a phase-locked-loop would eliminate phase offset between the locallygenerated 6.5 GHz RF carrier and the received RF signal, however in this evaluation, an electrical delay line was used with a copy of the RF carrier (from the cluster node) to implement the required phase correction. This down-converted signal at the switch node was used to modulate the directly-modulated L-band VCSEL. The free-running VCSEL was biased far from threshold and operated within its linear voltage input range; it operated without temperature control or wavelength stabilization. An optical power meter (OPM) at the VCSEL output was used to ensure that the cleaved fiber and the VCSEL aperture were aligned optimally. An optical spectrum analyzer (OSA) was used to verify a clean optical signal into the BIF. The $1 \mathrm{~km}$ BIF used between switch and gateway nodes had an attenuation of $1.2 \mathrm{~dB}$. At the gateway receiver, a variable optical attenuator was used to adjust the input power into the photo diode (PD). Post-PD amplification was used to ensure sufficient voltage swing into the bit error rate tester (BERT) device, and post-PD low-pass filtering at $1.8 \mathrm{GHz}$ was implemented to improve the signal to noise ratio (SNR). System performance was characterized using eye diagram observations and a BER sensitivity to PD input power assessment.

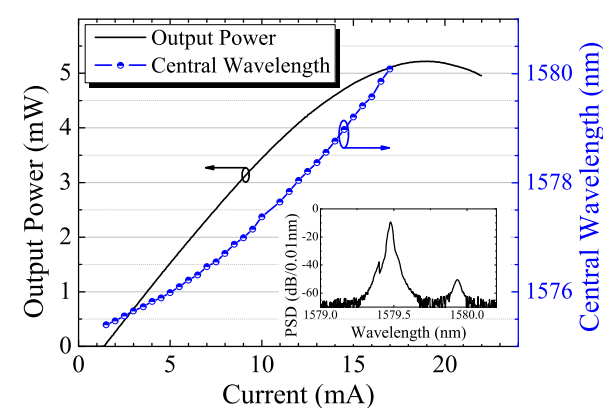

(a)

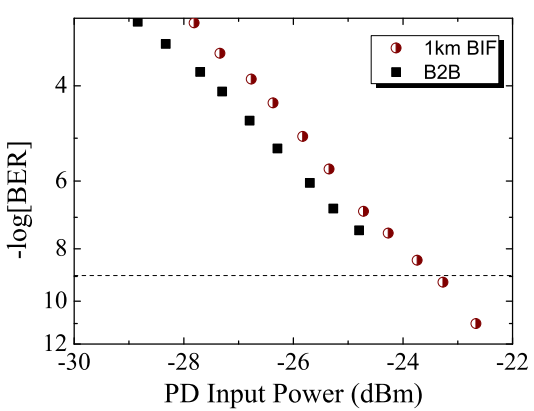

(b)

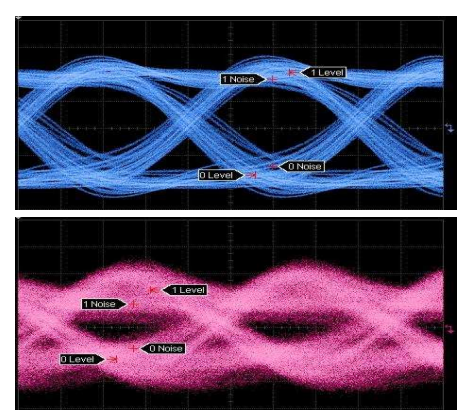

(c)

Fig. 1. (a)DC response of free-running $1580 \mathrm{~nm}$ VCSEL; power (black triangles) and wavelength (blue circles) variation with bias current. Inset: sample optical spectrum obtained at the VCSEL output; (b) BER sensitivity to PD input power, for B2B (black square) and $1 \mathrm{~km} \mathrm{BIF}$ (red, circle); (c) eyes observed at switch antenna (blue, top), after $1 \mathrm{~km}$ BIF (pink, lower).

\section{Results}

The BER sensitivity to PD input power characteristic is shown in Fig. 1b, eye diagram observations are presented in Fig. 1C. We observed error-free transmission through the hybrid radio/fiber link at a received optical power of $23.4 \mathrm{dBm}$ after $1 \mathrm{~km}$ BIF transmission; optical transmission margin of $20.95 \mathrm{~dB}$ was obtained. From the eye diagrams 


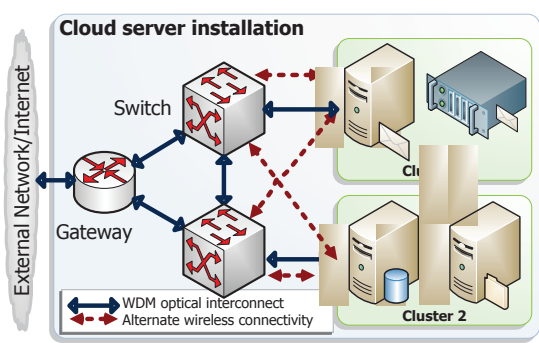

(a)
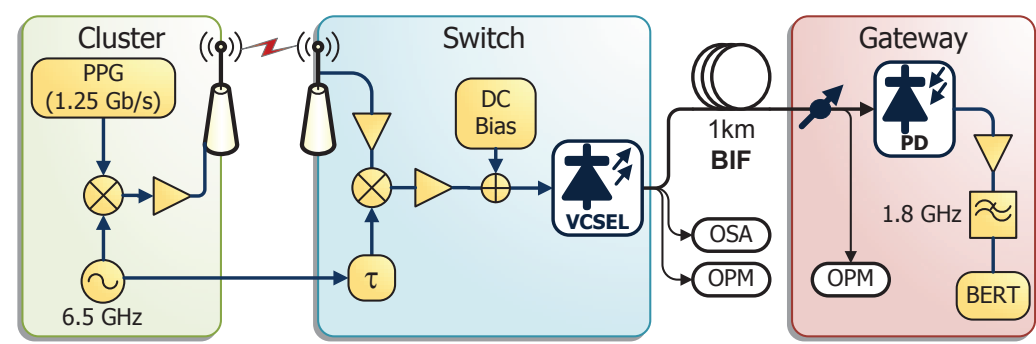

(b)

Fig. 2. (a) Cloud-server architecture implementing WDM optical interconnect with alternate wireless connectivity. (b) experimental layout: BERT, bit error rate tester; BIF, bend insensitive fiber; OPM, optical power meter; OSA, optical spectrum analyzer; PPG, pulse pattern generator.

shown in Fig. 1c the signal obtained after wireless transmission and down-conversion at the switch node had a clear open eye (blue, top) with $6.58 \mathrm{~dB}$ SNR and a peak to peak voltage (Vpp) of $340.4 \mathrm{mV}$. After further transmission through $1 \mathrm{~km}$ fiber and photo-detection at the gateway node, the signal obtained (pink, lower) presented a clear open eye and had $2.75 \mathrm{~dB}$ SNR. A transmission power penalty below $1 \mathrm{~dB}$ was observed after $1 \mathrm{~km}$ BIF.

\section{Conclusion}

We have demonstrated the use of a novel L-band VCSEL device in achieving error-free data transmission over a hybrid radio/fiber link in a cloud optical interconnect; $1.25 \mathrm{Gbps}$ was achieved over $55 \mathrm{~cm}$ air link followed by a free-running $1580 \mathrm{~nm}$ VCSEL and $1 \mathrm{~km}$ G.657 BIF. Longer-distance wireless transmission could have been achieved with higher-gain amplifiers. The L-band VCSEL used was operated without temperature control, enabling it to implement compact, energy-efficient broadband transceivers suitable for deployment in WDM optical interconnects for high-density cloud data service installations. The successful implementation of such hybrid radio/fiber links into a WDM optical interconnect highlights the flexibility of the VCSEL device used, and significantly improves connectivity, reliability and performance of cloud service architectures. The low transmission penalty encourages further investigations of VCSEL usability in interconnect applications. These results encourage further investigations into the potential of WDM optical interconnects to support cloud delivery systems, with reduced energy consumption.

\section{References}

[1] P. Pepeljugoski et al., "Data center and high performance computing interconnects for $100 \mathrm{~Gb} / \mathrm{s}$ and beyond," in Proc. OFC, 2007, Paper OMR4.

[2] M. Haurylau et al., "On-chip optical interconnect roadmap: Challenges and critical directions," IEEE J. Quantum Electron., vol. 12, pp. 1699-1705, 2006.

[3] A. Benner et al, "Explotation of optical interconnects in future server architectures," IBM J. Res. and Devel., vol. 49, no. 4, pp. $755-775$, Jul. 2005.

[4] T. Bohnert et al., "Optical networking for cloud computing," in Proc. OFC, Los Angeles, USA, 2011 , Paper OTuG3.

[5] D. Verchere, "Cloud computing over telecom network," in Proc. OFC, Los Angeles, USA, 2011, Paper OMW1.

[6] M. Ritter, "Virtualized optical networks for sustainable cloud services," ADVA white paper, 2011.

[7] P. Gill et al., "Understanding Network Failures in Data Centers: Measurement, Analysis, and Implications," in Proc. SIGCOMM 2011.

[8] ITU-T recommendation G.657, Nov. 2009.

[9] J. Guillory et al., "Radio over fiber tunnel for $60 \mathrm{GHz}$ wireless home network," in Proc. OFC, 2011, Paper OWT6.

[10] A. Ngoma et al., "Performance of a multi-Gb/s $60 \mathrm{GHz}$ radio over fiber system employing a directly modulated optically injection-locked VCSEL," J. Lightw. Technol., vol. 28, no. 16, pp. 2436-2444, August 2010.

[11] A.Caballero et al, "Impulse radio ultra wide-band over multi-mode fiber for in-home signal distribution," MWP 2009.

[12] S.Saldaña et al, "L-band free-running 10.7Gbps directly-modulated VCSEL for WDM interconn.," sent to ICC 2012. 